Article

\title{
Opioid-Related Diagnoses and Concurrent Claims for HIV, HBV, or HCV among Medicare Beneficiaries, United States, 2015
}

\author{
Man-Huei Chang ${ }^{1, *}$, Ramal Moonesinghe ${ }^{2} \mathbb{D}$, Lyna Z. Schieber ${ }^{3}$ and Benedict I. Truman ${ }^{1}$ \\ 1 National Center for HIV/AIDS, Viral Hepatitis, STD, and TB Prevention, Centers for Disease Control and \\ Prevention (CDC), Atlanta, Georgia, GA 30329, USA; bit1@cdc.gov \\ 2 Office of Minority Health and Health Equity, CDC, Atlanta, Georgia, GA 30341, USA; zor7@cdc.gov \\ 3 National Center for Injury Prevention and Control, CDC, Atlanta, Georgia, GA 30341, USA; chn6@cdc.gov \\ * Correspondence: mdc9@cdc.gov
}

Received: 12 September 2019; Accepted: 21 October 2019; Published: 24 October 2019

\begin{abstract}
Unsterile opioid injection increases risk for infection transmission, including HIV, hepatitis $B$ virus (HBV), or hepatitis $C$ virus (HCV). We assess prevalence of and risk factors associated with opioid overdose and infections with HIV, HBV, or HCV among Medicare beneficiaries with opioid-related fee-for-service claims during 2015. We conducted a cross-sectional analysis to estimate claims for opioid use and overdose and HIV, HBV, or HCV infections, using data from US Medicare fee-for-service claims. Beneficiaries with opioid-related claims had increased odds for HIV (2.3; 95\% confidence interval (CI), 2.3-2.4), acute HBV (6.7; 95\% CI, 6.3-7.1), chronic HBV (5.0; 95\% CI, 4.7-5.4), acute HCV (9.6; 95\% CI, 9.2-10.0), and chronic HCV (8.9; 95\% CI, 8.7-9.1). Beneficiaries with opioid-related claims and for HIV, HBV, or HCV infection, respectively, had a 1.1-1.9-fold odds for having a claim for opioid overdose. Independent risk factors for opioid overdose and each selected infection outcome included age, sex, race/ethnicity, region, and residence in a high-vulnerability county. Having opioid-related claims and selected demographic attributes were independent, significant risk factors for having HIV, HBV, or HCV claims among US Medicare beneficiaries. These results might help guide interventions intended to reduce incidences of $\mathrm{HIV}, \mathrm{HCV}$, and $\mathrm{HBV}$ infections among beneficiaries with opioid-related claims.
\end{abstract}

Keywords: health status disparities; socioeconomic factors; infectious disease medicine; Medicare

\section{Introduction}

The US opioid crisis has increased incidence of opioid-related harms, unsterile injection-drug use (IDU), infections with hepatitis C (HCV), hepatitis B (HBV), HIV, and other outcomes [1,2]. In 2017, the Centers for Disease Control and Prevention (CDC) estimated a total of 70,237 drug overdose deaths, of which 47,600 (67.8\%) involved opioids, and during 2016-2017, synthetic opioid-involved overdose death rates increased $45.2 \%$ [3].

Illicit opioid injection increases risk for infectious disease transmission, especially bloodborne infections [4]. Approximately 9\% of 39,782 new diagnoses of HIV in the United States during 2016 were attributable to IDU or male-to-male sexual contact and IDU [5]. Bloodborne infections are more prevalent and often more severe among persons addicted to opioids than among the general population [6-8].

$\mathrm{HCV}$ infection is the underlying or contributing cause of more deaths than any other infection [9], and the number of new HCV infections tripled during 2010-2016 [10]. The nationwide increase in acute HCV infection is related to the country's opioid overdose epidemic and associated increases in 
IDU [11-13]. A 133\% increase in acute HCV cases during 2004-2014 was associated with increases in opioid injection [14], and an estimated 20,900 new cases of acute HBV infection occurred during 2016 [10].

National data indicate increasing opioid misuse among older adults [15]. Effects among older adults who take prescription medications [16-18] and vulnerable populations (e.g., persons who inject drugs) in economically disadvantaged areas [19] have been described. Opioid-related inpatient stays and emergency department visits among patients aged $\geq 65$ years increased $34.3 \%$ and $74.2 \%$, respectively, during 2010-2015 [16]. Recently, the Centers for Medicare and Medicaid Services (CMS) released proposed changes for the Medicare health and Part D benefit plans to reduce opioid overdose risk [20].

Attributes of Medicare beneficiaries with claims for coincident HIV or hepatitis infection and opioid-related harms have not been adequately described in the literature, and the factors associated with claims settled in 2015 for these infections or opioid overdose among beneficiaries are unknown. To address these knowledge gaps, we assessed (a) numbers and percentages of Medicare fee-for-service (FFS) beneficiaries with opioid-related claims or opioid overdose by age, sex, race/ethnicity, US census region of residence, and county of residence rated by vulnerability index [19] for IDU-related HIV and HCV outbreaks; (b) the association of claims for HIV infection and acute or chronic HBV and HCV infections with opioid-related claims; (c) factors associated with opioid overdose among beneficiaries with non-overdose opioid-related claims and with HIV, HBV, or HCV infection; and (d) factors associated with claims for heroin overdose among beneficiaries with non-overdose opioid-related claims.

\section{Methods}

\subsection{Data Sources and Populations}

We used the Medicare administrative enrollment and claims data [21] collected by CMS to estimate $\mathrm{HIV}, \mathrm{HBV}$, or HCV infections among beneficiaries who had FFS health insurance claims settled during 2015 (latest data availability year). We estimated the infection burden in 5 categories (Table A1): (a) $\mathrm{HIV}$, (b) acute HBV, (c) chronic HBV, (d) acute HCV, and (e) chronic HCV; we also compared claims for $\geq 1$ of these 5 infections with 0 claims. To identify these infections, we used diagnosis codes for beneficiaries who had $\geq 1$ inpatient claim or $\geq 2$ outpatient claims spaced $\geq 1$ month apart [22]. The opioid-related and infection diagnoses were coded according to the International Classification of Diseases, 9th Revision, Clinical Modification (ICD-9-CM) [23] for the first three quarters of 2015 or the 10th Revision (ICD-10-CM) [24] for the fourth quarter.

We estimated numbers of beneficiaries with opioid-related claims for 2 diagnosis categories: (a) opioid abuse or opioid dependence and unspecified use (categorized and labelled opioid-related claims (ORCs)); and (b) opioid poisoning (categorized and labelled opioid overdose) (Table A2) [25]. Beneficiaries with ORCs had $\geq 1$ inpatient claim or $\geq 2$ outpatient claims spaced $\geq 1$ month apart with $\geq 1$ prespecified diagnosis code, and for opioid overdose, had $\geq 1$ inpatient or outpatient claim with $\geq 1$ prespecified diagnosis code. Beneficiaries with ORCs or opioid overdose were identified separately using a series of ICD-CM codes in multiple diagnosis fields in outpatient and inpatient clams based on the prespecified criteria. We classified each beneficiary as Yes/No for having or not having a claim for each category of opioid-related diagnosis or infection. We examined associations of ORCs, opioid overdose, and each infection by age group ( $\leq 64,65-74$, or $\geq 75$ years), sex (male or female), race/ethnicity (non-Hispanic white, non-Hispanic black, Hispanic, Asian/Pacific Islander, American Indian/Alaska Native, or other/unknown), and US census region of residence (Northeast, West, Midwest, or South). We also estimated frequencies of persons with opioid-related claims residing in each county classified by vulnerability score (Vulnerable, the $5 \%$ of counties with the highest vulnerability, or Other) for HIV or HCV infections (scores are calculated for all US counties by assessing 15 indicators that can be associated with rapid dissemination of HIV or HCV infection through IDU) [19]. 


\subsection{Analysis}

We first analyzed demographic characteristics for beneficiaries with ORCs and calculated percentages of beneficiaries with or without each type of opioid-related claim among those who had or did not have HIV, HBV, or HCV claims. Second, we estimated the percentage of beneficiaries with claims for opioid overdose among those who had ORC claims. Third, we calculated percentages of persons with each type of opioid-related claim separately by demographic attributes of Medicare FFS enrollees who had or did not have claims for any of each category of selected infection. Fourth, we used multivariable logistic regression to examine the association of HIV, HBV, or HCV infection separately with ORC while controlling for age, sex, race/ethnicity, US census region of residence, and county-level vulnerability scores in the model. Fifth, we identified factors associated with claims for opioid overdose among beneficiaries with ORCs and compared the odds ratios of opioid overdose among beneficiaries with claims for each category of infection versus without infection. Similarly, we compared odds ratios of opioid overdose among beneficiaries with claims for $\geq 1$ infection versus none of the 5 infections. Lastly, we examined associations of claims for heroin overdose with each infection among beneficiaries with ORCs. All analyses were performed by using SAS ${ }^{\circledR} 9.4$ and SAS Enterprise Guide ${ }^{\circledR} 7.1$ (SAS Institute, Inc., Cary, North Carolina) in the secured environment of the CMS Virtual Research Data Center through the Chronic Conditions Warehouse [26].

\section{Results}

\subsection{Population Attributes of Beneficiaries with Concurrent Claims for Selected Infections and Opioid-Related Diagnoses}

Of 40.6 million beneficiaries with FFS claims settled during 2015, 263,709 (0.6\%) had ORCs, and $46,073(0.1 \%)$ had claims for opioid overdose (Table 1). Compared with beneficiaries without opioid-related claims, those with claims had significantly different $(p<0.05)$ distributions by age group, sex, race/ethnicity, residence census region, and county vulnerability score. Among beneficiaries with ORCs, the majority were aged $<75$ years $(89.3 \%)$, female $(54.3 \%)$, non-Hispanic white $(78.2 \%)$, residing in the South $(45.2 \%)$, and not residing in vulnerable counties $(93.6 \%)$. Similar differences in demographic distribution patterns were observed for beneficiaries with opioid overdose claims.

Among beneficiaries with FFS claims, small percentages had claims for HIV infection $(0.3 \%)$, acute HBV $(0.05 \%)$, chronic HBV $(0.06 \%)$, acute HCV $(0.05 \%)$, chronic HCV $(0.4 \%)$, or $\geq 1$ of these 5 infections $(0.8 \%)$ (Table S1 in the Supplement). Percentages of beneficiaries with opioid-related claims were significantly higher $(p<0.05)$ among those with claims for HIV, HBV, or HCV infection, compared with those without claims for the infections studied (Figure 1A; Table S1). The pattern observed for beneficiaries with claims for opioid overdose was similar to that observed for beneficiaries with ORCs (Figure 1B; Table S1). Among beneficiaries with opioid overdose claims, 32.7\% also had ORCs (Table S2 in the Supplement).

Table 2 and Table S3 in the Supplement present the percentages of beneficiaries with ORCs or opioid overdose claims by demographics among beneficiaries with or without any of the 6 categories of infection. Among beneficiaries who had HIV claims, 3.9\% had ORCs; this percentage increased to $12.1 \%$ among those who had claims for acute HCV infection (Table 2). The highest percentages of beneficiaries with ORC claims among enrollees with HIV claims were among persons aged $\leq 64$ years $(4.4 \%)$, female $(4.5 \%)$, Hispanic $(4.3 \%)$, and residing in the Northeast $(6.5 \%)$ and in counties with a high vulnerability score. Among beneficiaries with HBV or HCV claims, the highest percentages of beneficiaries having ORCs were aged $\leq 64$ years, male, non-Hispanic white, and residing in the Northeast and in vulnerable counties. For acute HCV, $17.1 \%$ having ORCs were aged $\leq 64$ years versus $<2 \%$ among those aged $\geq 75$ years. The percentage of beneficiaries having ORCs was slightly higher among males than females among HBV-infected beneficiaries (acute, $7.2 \%$ for males versus $5.1 \%$ for females; chronic, $4.2 \%$ for males versus $2.8 \%$ for females). Similarly, males had a slightly higher percentage of ORCs among HCV-infected beneficiaries. Non-Hispanic whites with claims for acute 
and chronic HBV or chronic HCV had more frequent claims with diagnostic codes for ORCs than other racial/ethnic groups. The percentage of ORCs among beneficiaries who had claims for HIV infection was approximately the same among Hispanics and non-Hispanic whites. Asian/Pacific Islanders had the lowest percentage of ORCs than any other racial/ethnic group with HBV or HCV infections or $\geq 1$ of the 5 infections versus none.

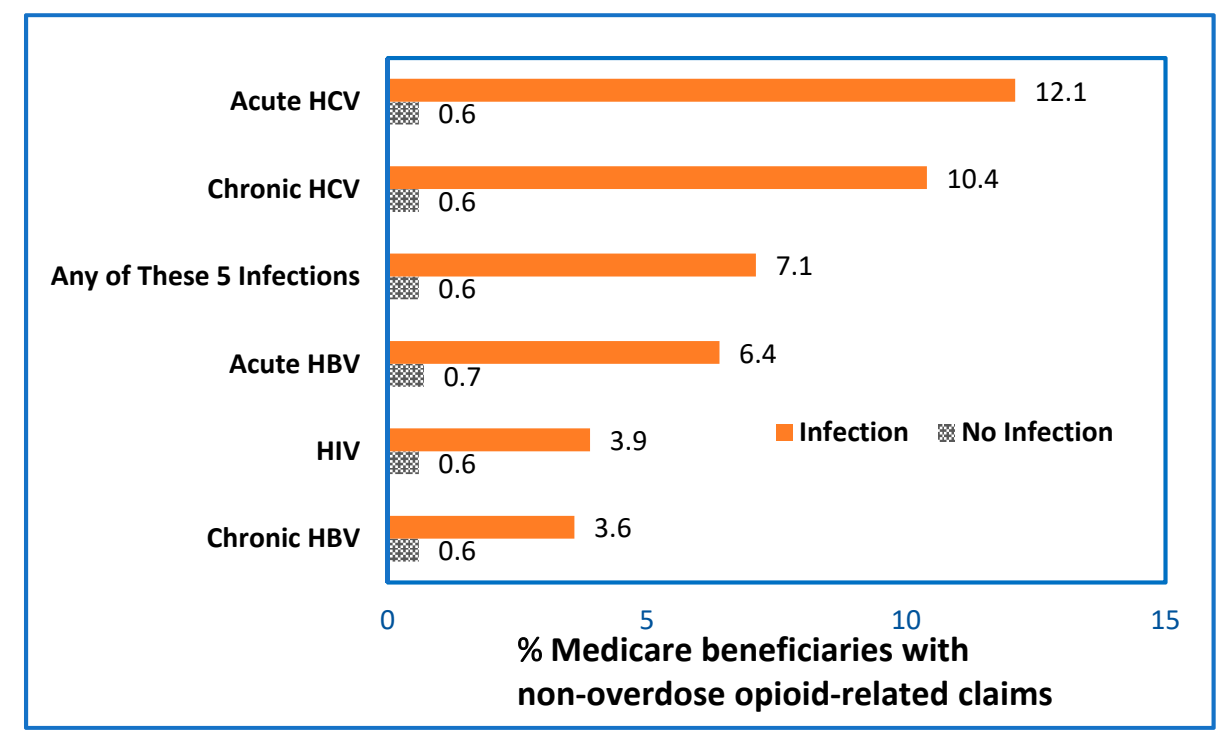

(A)

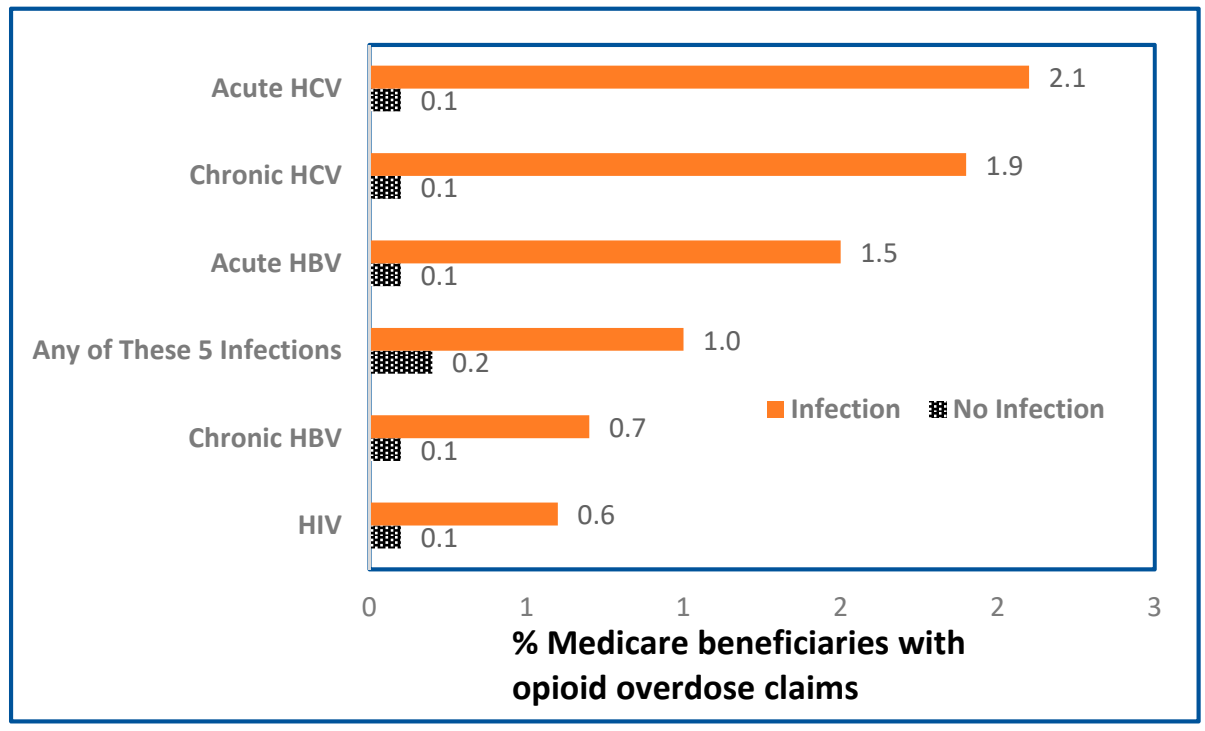

(B)

Figure 1. Percentage of Medicare beneficiaries with opioid-related claims among beneficiaries without (A) or with (B) claims for HIV, HBV, or HCV, United States, 2015; ( $n=40.6$ million beneficiaries with FFS claims for non-overdose opioid-related diagnoses). Abbreviations: FFS, fee-for service, HBV, hepatitis B virus; $\mathrm{HCV}$, hepatitis $\mathrm{C}$ virus, $\mathrm{HIV}$, human immunodeficiency virus. Data were calculated from 40.6 million beneficiaries with fee-for-service claims from Medicare administrative enrollment and claims data collected by the Centers for Medicare and Medicaid Services during 2015. Each beneficiary was classified as Yes/No for having or not having a claim for each category of opioid-related diagnoses or selected infection (HIV, HBV, or HCV infections). The bar labelled "Any of These 5 Infections" indicates that claims involved $\geq 1$ of the 5 infections studied: HIV, acute or chronic HBV, and acute or chronic HCV. 
Table 1. Percentage of Medicare fee-for-service beneficiaries with and without claims ${ }^{\text {a }}$ for opioid-related diagnoses, by demographic attributes, United States, 2015.

\begin{tabular}{|c|c|c|c|c|c|}
\hline \multirow{3}{*}{ Characteristic } & \multicolumn{2}{|c|}{ Non-Overdose Opioid-Related Claim ${ }^{b, c}$} & \multicolumn{2}{|c|}{ Opioid Overdose Claim ${ }^{b, c}$} & \multirow{2}{*}{ Total } \\
\hline & Yes & No & Yes & No & \\
\hline & $\begin{array}{c}0.65 \% \\
(n=263,709)\end{array}$ & $\begin{array}{c}99.35 \% \\
(n=40.3 \mathrm{M})\end{array}$ & $\begin{array}{c}0.11 \% \\
(n=46,073)\end{array}$ & $\begin{array}{c}99.89 \% \\
(n=40.5 \mathrm{M})\end{array}$ & $\begin{array}{c}100.00 \% \\
(n=40.6 \mathrm{M})\end{array}$ \\
\hline \multicolumn{6}{|l|}{ Age (years), \% } \\
\hline$\leq 64$ & 66.7 & 16.7 & 58.4 & 17.0 & 17.1 \\
\hline $65-74$ & 22.6 & 47.1 & 25.4 & 47.0 & 47.0 \\
\hline$\geq 75$ & 10.7 & 36.2 & 16.2 & 36.0 & 36.0 \\
\hline \multicolumn{6}{|l|}{ Sex } \\
\hline Male & 45.7 & 46.6 & 42.0 & 46.6 & 46.6 \\
\hline Female & 54.3 & 53.4 & 58.0 & 53.4 & 53.4 \\
\hline \multicolumn{6}{|l|}{ Race/ethnicity, \% } \\
\hline Non-Hispanic white & 78.2 & 77.6 & 79.4 & 77.6 & 77.6 \\
\hline Non-Hispanic black & 13.3 & 9.9 & 12.1 & 9.9 & 9.9 \\
\hline Hispanic & 5.8 & 7.0 & 5.6 & 7.0 & 7.0 \\
\hline Asian/Pacific Islander & 0.6 & 2.9 & 0.7 & 2.9 & 2.9 \\
\hline American Indian/Alaska Native & 1.0 & 0.6 & 1.1 & 0.6 & 0.6 \\
\hline Other/unknown & 1.1 & 2.2 & 1.1 & 2.1 & 2.1 \\
\hline \multicolumn{6}{|l|}{ US census region of residence, $\%$} \\
\hline Northeast & 19.7 & 18.6 & 18.1 & 18.6 & 18.6 \\
\hline West & 18.6 & 19.2 & 18.5 & 19.2 & 19.2 \\
\hline Midwest & 16.5 & 22.0 & 21.8 & 22.0 & 22.0 \\
\hline South & 45.2 & 38.4 & 41.6 & 38.5 & 38.5 \\
\hline \multicolumn{6}{|c|}{ County of residence by vulnerability score ${ }^{\mathrm{d}}$} \\
\hline Highest vulnerability & 6.4 & 3.0 & 4.3 & 3.0 & 3.0 \\
\hline Other & 93.6 & 97.0 & 95.7 & 97.0 & 97.0 \\
\hline
\end{tabular}

M, million. a Diagnosis code used for $\geq 1$ inpatient claim or $\geq 2$ outpatient claims spaced $\geq 1$ month apart.; ${ }^{\mathrm{b}}$ Significantly different distributions by demographics at a 2-tailed Chi-square test with $p<0.05$; ${ }^{\mathrm{c}}$ Each beneficiary was classified as Yes/No for having or not having a claim for each category of opioid-related diagnoses or opioid overdose; ${ }^{\mathrm{d}}$ County vulnerability scores were reported by Van Handel et al in 2016. The top 5\% of counties with the highest vulnerability scores were classified as Highest vulnerability, and the remaining 95\% of counties were classified as Other. 
Table 2. Number and percentage of beneficiaries with opioid-related claims, ${ }^{a}$ by demographic characteristics among the Medicare fee-for-service beneficiaries who had or did not have HIV, HBV, or HCV claims, ${ }^{\text {a,b }}$ United States, 2015.

\begin{tabular}{|c|c|c|c|c|c|c|c|c|c|c|c|c|c|}
\hline \multirow[b]{2}{*}{ Infection Status } & \multicolumn{2}{|c|}{ HIV } & \multicolumn{2}{|c|}{ Acute HBV } & \multicolumn{2}{|c|}{ Chronic HBV } & \multicolumn{2}{|c|}{ Acute HCV } & \multicolumn{2}{|c|}{ Chronic HCV } & \multicolumn{2}{|c|}{ These 5 Infections } & \multirow[b]{2}{*}{ Total } \\
\hline & Yes & No & Yes & No & Yes & No & Yes & No & Yes & No & $\begin{array}{c}\geq 1 \\
\text { Infection }\end{array}$ & $\begin{array}{l}\text { None of } \\
\text { These } 5 \\
\text { Infections }\end{array}$ & \\
\hline $\begin{array}{c}\text { Number of } \\
\text { beneficiaries }\end{array}$ & 119312 & $40.4 \mathrm{M}$ & 19553 & $40.5 \mathrm{M}$ & 23671 & $40.5 \mathrm{M}$ & 20322 & $40.5 \mathrm{M}$ & 165159 & $40.4 \mathrm{M}$ & 311657 & $40.3 \mathrm{M}$ & $40.6 \mathrm{M}$ \\
\hline $\begin{array}{l}\text { Percentage (number) } \\
\text { of beneficiaries with } \\
\text { Opioid-Related Claims }\end{array}$ & $\begin{array}{c}3.90(n= \\
4655)\end{array}$ & $\begin{array}{l}0.64(n= \\
259,054)\end{array}$ & $\begin{array}{l}6.42(n= \\
1255)\end{array}$ & $\begin{array}{l}0.65(n= \\
262,454)\end{array}$ & $\begin{array}{c}3.64(n= \\
861)\end{array}$ & $\begin{array}{l}0.65(n= \\
262,848)\end{array}$ & $\begin{array}{c}12.13(n= \\
2466)\end{array}$ & $\begin{array}{l}0.64(n= \\
261,243)\end{array}$ & $\begin{array}{c}10.42(n= \\
17,214)\end{array}$ & $\begin{array}{l}0.61(n= \\
246,495)\end{array}$ & $\begin{array}{c}7.09(n= \\
22,111)\end{array}$ & $\begin{array}{l}0.60(n= \\
241,598)\end{array}$ & $\begin{array}{l}0.65(n= \\
263,709)\end{array}$ \\
\hline \multicolumn{14}{|l|}{ Characteristic } \\
\hline \multicolumn{14}{|l|}{ Age (years), \% } \\
\hline$\leq 64$ & 4.4 & 2.5 & 11.9 & 2.5 & 7.9 & 2.5 & 17.1 & 2.5 & 14.6 & 2.4 & 9.4 & 2.4 & 2.55 \\
\hline $65-74$ & 2.6 & 0.3 & 2.9 & 0.3 & 1.9 & 0.3 & 6.5 & 0.3 & 5.9 & 0.3 & 4.3 & 0.3 & 0.31 \\
\hline$\geq 75$ & 0.6 & 0.4 & 0.9 & 0.4 & 0.5 & 0.4 & 1.8 & 0.4 & 1.8 & 0.4 & 1.3 & 0.4 & 0.35 \\
\hline \multicolumn{14}{|l|}{ Sex, \% } \\
\hline Male & 3.7 & 0.6 & 7.2 & 0.6 & 4.2 & 0.6 & 12.8 & 0.6 & 11.0 & 0.6 & 7.1 & 0.6 & 0.6 \\
\hline Female & 4.5 & 0.7 & 5.1 & 0.7 & 2.8 & 0.7 & 11.2 & 0.7 & 9.5 & 0.6 & 7.2 & 0.6 & 0.7 \\
\hline \multicolumn{14}{|l|}{ Race/ethnicity, \% } \\
\hline Non-Hispanic white & 4.1 & 0.7 & 9.7 & 0.7 & 7.3 & 0.7 & 13.8 & 0.7 & 11.9 & 0.6 & 9.0 & 0.6 & 0.7 \\
\hline Non-Hispanic black & 3.9 & 0.8 & 5.9 & 0.9 & 5.0 & 0.9 & 9.5 & 0.9 & 8.0 & 0.8 & 5.2 & 0.8 & 0.9 \\
\hline Hispanic & 4.3 & 0.5 & 0.5 & 0.5 & 4.7 & 0.5 & 11.8 & 0.5 & 11.0 & 0.5 & 7.0 & 0.5 & 0.5 \\
\hline Asian/Pacific Islander & 1.8 & 0.1 & 0.2 & 0.1 & 0.1 & 0.1 & 2.4 & 0.1 & 1.6 & 0.1 & 0.7 & 0.1 & 0.1 \\
\hline $\begin{array}{c}\text { American } \\
\text { Indian/Alaska Native }\end{array}$ & 1.6 & 1.2 & 7.8 & 1.2 & 4.7 & 1.2 & 14.5 & 1.2 & 11.6 & 1.1 & 9.0 & 1.1 & 1.2 \\
\hline Other/unknown & 1.2 & 0.3 & 2.0 & 0.3 & 0.8 & 0.3 & 9.9 & 1.1 & 7.0 & 0.3 & 3.9 & 0.3 & 0.3 \\
\hline \multicolumn{14}{|l|}{$\begin{array}{c}\text { US census region, by } \\
\text { state, } \%\end{array}$} \\
\hline Northeast & 6.5 & 0.7 & 6.9 & 0.7 & 4.9 & 0.7 & 16.5 & 0.7 & 15.6 & 0.6 & 10.3 & 0.6 & 0.7 \\
\hline West & 3.1 & 0.6 & 4.1 & 0.6 & 1.9 & 0.6 & 9.5 & 0.6 & 9.1 & 0.6 & 6.2 & 0.6 & 0.6 \\
\hline Midwest & 3.3 & 0.5 & 6.8 & 0.5 & 4.6 & 0.5 & 11.8 & 0.5 & 9.4 & 0.5 & 6.9 & 0.5 & 0.5 \\
\hline South & 3.1 & 0.8 & 7.4 & 0.8 & 4.5 & 0.8 & 11.1 & 0.8 & 8.8 & 0.7 & 6.0 & 0.7 & 0.8 \\
\hline \multicolumn{14}{|l|}{$\begin{array}{c}\text { County vulnerability } \\
\text { score }{ }^{c}, \%\end{array}$} \\
\hline Highest vulnerability & 4.2 & 1.4 & 20.0 & 1.4 & 12.3 & 1.4 & 19.9 & 1.4 & 15.8 & 1.4 & 13.5 & 1.4 & 1.4 \\
\hline Other & 3.9 & 0.6 & 6.0 & 0.6 & 3.5 & 0.6 & 11.9 & 0.6 & 10.3 & 0.6 & 7.0 & 0.6 & 0.6 \\
\hline
\end{tabular}

Abbreviations: HBV, hepatitis B virus; HCV, hepatitis C virus; M, million. ${ }^{a}$ Diagnosis code used $\geq 1$ inpatient claim or $\geq 2$ outpatient claims spaced $\geq 1$ month apart. ${ }^{b}$ Each beneficiary was classified as Yes/No for having or not having a claim for each category of opioid-related diagnoses or selected infection (HIV, HBV, or HCV infections). The table label "Any of these of infections" indicates claims involved $\geq 1$ of the 5 infections studied: HIV, acute or chronic HBV, and acute or chronic HCV. ${ }^{c}$ County vulnerability scores were reported by Van Handel et al in 2016. The top 5\% of counties with the highest vulnerability scores were classified as Highest vulnerability, and the remaining $95 \%$ of counties were classified as Other. 
Except for acute HBV (highest percentage of claims in the South), beneficiaries residing in the Northeast had the highest ORCs among those who had claims for HIV, chronic HBV, acute or chronic $\mathrm{HCV}$ infections, or $\geq 1$ of these 5 infections versus 0 infections (Table 2). Overall, beneficiaries residing in counties with the highest vulnerability scores had $>2$ times the ORCs than those who lived in other counties $(1.4 \%$ versus $0.6 \%)$. This percentage was even higher among beneficiaries with claims for HIV infection (4.2\%), acute HBV (20.0\%), chronic HBV (12.3\%), acute HCV (19.9\%), chronic HCV (15.8\%), or $\geq 1$ of the 5 infections (13.5\%) versus none of the infections.

Table S3 in the Supplement presents beneficiaries with claims for opioid overdose among those with HIV, HBV, or HCV infection claims. Among persons with claims for HIV, HBV, or HCV infection, the highest percentage of persons with opioid overdose was observed among those aged $\leq 64$ years and non-Hispanic whites or American Indian/Alaska Natives. However, certain variations in the percentages of having a claim for opioid overdose were observed by demographics among those with claims for HIV, HBV, or HCV infection. For example, for persons who resided in counties with the highest vulnerability scores versus those who resided in other counties, the percentage of persons who had a claim for opioid overdose was higher among those with claims for acute HBV ( $3.7 \%$ versus $1.4 \%$ ), chronic HCV ( $2.8 \%$ versus $1.8 \%)$, or $\geq 1$ infection (2.3\% versus $1.3 \%)$. However, this pattern was not observed for persons with claims for HIV and chronic HBV infection.

\subsection{Association of Claims for Selected Infections with Opioid-Related Claims}

A statistically significant association of having a claim for $\mathrm{HIV}, \mathrm{HBV}$, or $\mathrm{HCV}$ infection was observed among beneficiaries with ORCs after controlling for age, sex, race/ethnicity, US region of residence, and county-level vulnerability (Table 3). The odds of having a claim for HIV among beneficiaries with ORCs was more than twice (adjusted odds ratio (aOR), 2.3; 95\% confidence interval (CI), 2.3-2.4; $p<0.05$ ) that of those who did not have an ORC. This significant association was remarkably stronger among beneficiaries with claims for ORCs and acute $\mathrm{HBV}$ infection (aOR, 6.7; 95\% CI, 6.3-7.1), chronic HBV (aOR, 5.0; 95\% CI, 4.7-5.4), acute HCV infection (aOR, 9.6; 95\% CI, 9.2-10.0), or chronic HCV infection (aOR, 8.9; 95\% CI, 8.7-9.1). Beneficiaries with ORCs had approximately 6 times the odds of having a claim for $\geq 1$ of the 5 infections, compared with those who did not (aOR, 5.8; $95 \%$ CI, 5.7-5.9). Beneficiaries with ORCs with the selected demographic characteristics in this study were also significantly $(p<0.0001)$ associated with having a claim for these 6 infection categories.

\subsection{Factors Associated with Opioid Overdose among Beneficiaries with Opioid-Related Claims}

Beneficiaries with claims for ORCs and HIV, HBV, or HCV infection had a 1.1-1.9-fold odds of having a claim for opioid overdose, compared with those who did not (Table 4). By examining claims involving coinfection with $\geq 1$ of the 5 infections among beneficiaries with ORCs, beneficiaries with $\geq 1 \mathrm{HIV}, \mathrm{HBV}$, or HCV infection had twice the odds (aOR, 2.0; 95\% CI, 1.9-2.1) of having claims for opioid overdose, compared with those who had none of these infections (Table S4 in the Supplement). A similar pattern of association between claims for heroin overdose with bloodborne infections was observed, but its association was even stronger for acute (aOR, 2.4; 95\% CI, 1.8-3.0) or chronic HBV (aOR, $1.4 ; 95 \% \mathrm{CI}, 1.0-2.0$ ), or acute (aOR, 1.5; 95\% CI, 1.2-1.8) or chronic HCV (aOR, $2.7 ; 95 \% \mathrm{CI}$, 2.5-3.0) (Table S5 in the Supplement). 
Table 3. Adjusted odds ratios (aORs) and 95\% confidence intervals (CIs) for association of claims for HIV, HBV, or HCV infections with non-overdose opioid-related claims or each demographic attribute of Medicare beneficiaries, United States, 2015.

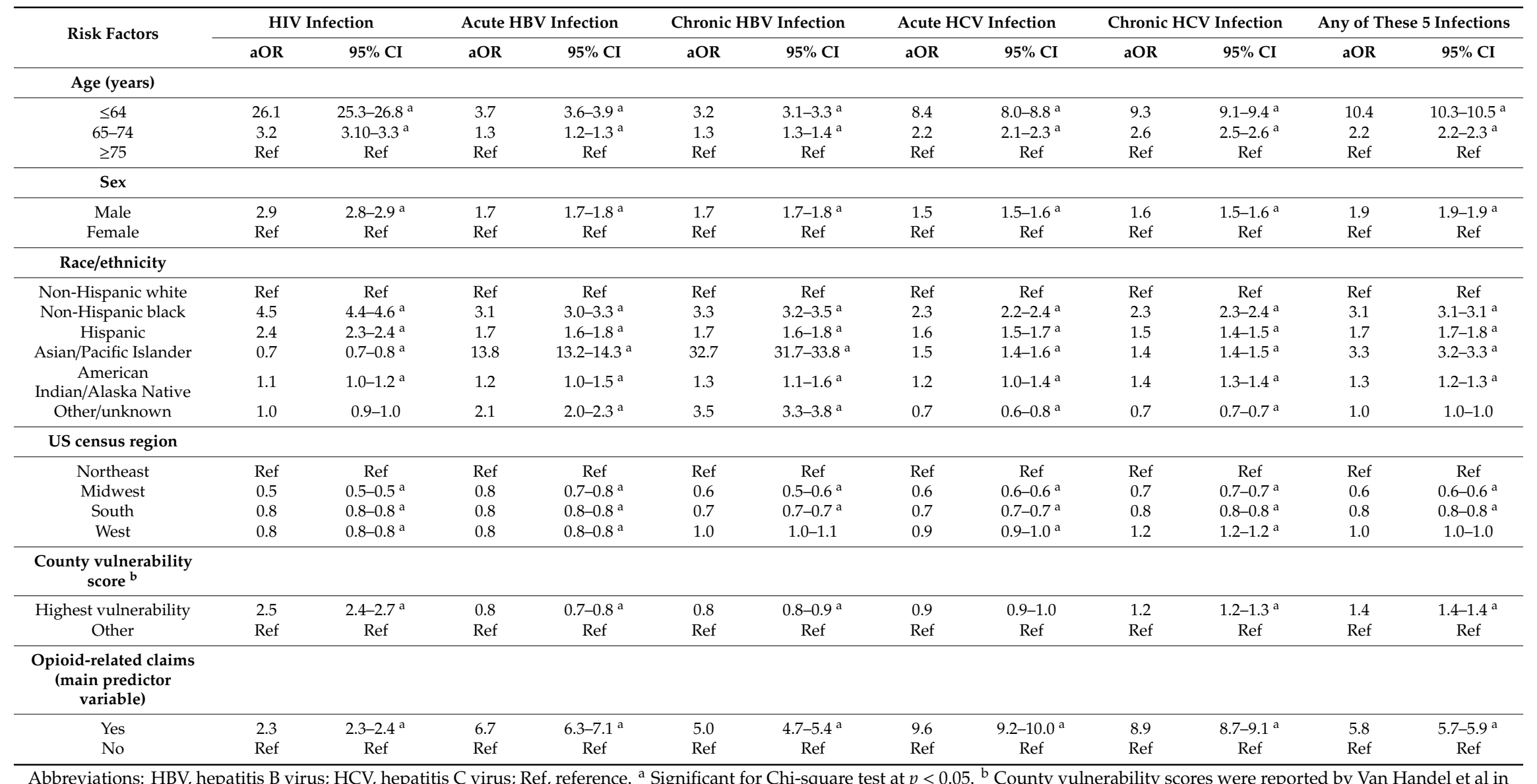

2016. The top $5 \%$ of counties with the highest vulnerability scores were classified as Highest vulnerability, and the remaining $95 \%$ of counties were classified as Other. 
Table 4. Adjusted odds ratios (aORs) and 95\% confidence intervals (CIs) for association of opioid overdose claims with each demographic attribute of Medicare beneficiaries with claims for opioid-related diagnoses, United States, 2015.

\begin{tabular}{|c|c|c|}
\hline \multirow{2}{*}{ Characteristic } & \multicolumn{2}{|c|}{ Opioid Overdose } \\
\hline & $\mathrm{aOR}$ & $95 \% \mathrm{CI}$ \\
\hline \multicolumn{3}{|l|}{ Age (years) } \\
\hline$\leq 64$ & 1.9 & $1.7-2.0^{\mathrm{a}}$ \\
\hline $65-74$ & 1.5 & $1.4-1.7^{\mathrm{a}}$ \\
\hline$\geq 75$ & Ref & Ref \\
\hline \multicolumn{3}{|l|}{ Sex } \\
\hline Male & 1.0 & $0.9-1.0$ \\
\hline Female & Ref & Ref \\
\hline \multicolumn{3}{|l|}{ Race/ethnicity } \\
\hline Non-Hispanic white & Ref & Ref \\
\hline Non-Hispanic black & 0.8 & $0.8-0.9^{\mathrm{a}}$ \\
\hline Hispanic & 0.9 & $0.9-1.0^{\mathrm{a}}$ \\
\hline Asian/Pacific Islander & 0.8 & $0.6-1.0$ \\
\hline American Indian/Alaska Native & 1.1 & $0.9-1.2$ \\
\hline Other/unknown & 1.2 & $1.1-1.2^{\mathrm{a}}$ \\
\hline \multicolumn{3}{|l|}{ US census region } \\
\hline Northeast & Ref & Ref \\
\hline Midwest & 1.2 & $1.1-1.2^{\mathrm{a}}$ \\
\hline South & 0.8 & $0.7-0.8^{\mathrm{a}}$ \\
\hline West & 0.9 & $0.9-1.0^{\mathrm{a}}$ \\
\hline \multicolumn{3}{|l|}{ County vulnerability score ${ }^{b}$} \\
\hline Highest vulnerability & 1.4 & $1.3-1.6^{\mathrm{a}}$ \\
\hline Other & Ref & Ref \\
\hline \multicolumn{3}{|l|}{$\begin{array}{c}\text { Infection (primary predictor } \\
\text { variable) }\end{array}$} \\
\hline \multicolumn{3}{|l|}{ HIV } \\
\hline Yes & 1.1 & $1.0-1.2$ \\
\hline No & Ref & Ref \\
\hline \multicolumn{3}{|l|}{ Acute HBV } \\
\hline Yes & 1.9 & $1.6-2.3^{\mathrm{a}}$ \\
\hline No & Ref & Ref \\
\hline \multicolumn{3}{|l|}{ Chronic HBV } \\
\hline Yes & 1.2 & $1.0-1.5$ \\
\hline No & Ref & Ref \\
\hline \multicolumn{3}{|l|}{ Acute HCV } \\
\hline Yes & 1.3 & $1.2-1.5^{\mathrm{a}}$ \\
\hline No & Ref & Ref \\
\hline \multicolumn{3}{|l|}{ Chronic HCV } \\
\hline Yes & 1.9 & $1.8-2.0^{\mathrm{a}}$ \\
\hline No & Ref & Ref \\
\hline
\end{tabular}

Abbreviations: HBV, hepatitis B virus; $\mathrm{HCV}$, hepatitis C virus; Ref, reference. ${ }^{\text {a }}$ Significant for Chi-square test at $p<0.05$. ${ }^{\mathrm{b}}$ County vulnerability scores were reported by Van Handel et al in 2016 . The top $5 \%$ of counties with the highest vulnerability scores were classified as Highest vulnerability, and the remaining counties were classified as Other.

\section{Discussion}

Among 40.6 million beneficiaries with FFS claims during 2015, 0.6\% had non-overdose ORCs and $0.1 \%$ had opioid overdose claims. Among beneficiaries with opioid overdose claims, $32.7 \%$ also had ORCs. Beneficiaries with ORCs were substantially more likely than those without ORCs to be aged $<75$ years, female, non-Hispanic white, residents of the US South, and residents of counties less vulnerable to IDU-related HIV and HCV outbreaks. Beneficiaries with ORCs were more likely to have claims for HIV (2.3 times), acute HBV (6.7 times), chronic HBV (5.0 times), acute HCV (9.6 times), chronic HCV (8.9 times), or any 1 of those infections (5.8 times), when adjusted for age, sex, race/ethnicity, 
region of residence, and residence in counties with a high vulnerability index. Factors associated with opioid overdose included claims for acute $\mathrm{HBV}$, acute $\mathrm{HCV}$, and chronic $\mathrm{HCV}$, residence in a county with a high vulnerability score, residence in the US Midwest, other/unknown race/ethnicity, and age $<75$ years.

Our findings are consistent with recent evidence reported in previous studies about opioid use (e.g., $43.7 \%$ of disabled beneficiaries aged $\leq 64$ years reported prescription opioid use during 2011) [27]. Our data reveal that the highest percentage of beneficiaries with claims for ORCs and acute HBV infection resided in the South, but higher percentages of beneficiaries with claims for HIV, HCV, or chronic HBV infection resided in the Northeast. Recently, CDC reported that opioid overdose treated in emergency departments increased approximately $30 \%$ in the majority of states, with a peak of $70 \%$ in the Midwest during the 14 months before September 2017 [28]. Moreover, opioid prescribing increased for men and women in all age groups and in all census regions, but varied by states with rural/urban differences [29-31].

Our results extend previous studies and confirm that ORCs are strongly associated with the 6 categories of infection (i.e., HIV [32], acute or chronic HBV [33], and acute or chronic HCV [13]) [34,35]. Beneficiaries with claims for opioid-related diagnoses and acute HBV or acute or chronic HCV infection were 1-2 times as likely to have opioid overdose claims, compared with beneficiaries without these claims. For heroin overdoses, the association was even stronger, with the odds 1-3 times higher, compared with beneficiaries without the 5 infection claims. However, we did not observe claims for HIV infection to be independently associated with opioid overdose nor heroin overdose among beneficiaries with ORCs after adjusting for demographics and HBV or HCV infection.

Other studies have reported that patients with HIV infection are more likely to be prescribed opioids than uninfected persons [36,37], have an increased risk for opioid-related death [38,39], and have a higher prevalence of risk factors associated with major opioid-related adverse events (e.g., mental health or alcohol and substance use disorders) [40]. Correlation of high-dose opioid receipt was reported with HIV infection among aging patients [32,41]. Opioid use disorder has been reported to impair immune function [42], interact with antiretroviral agents in treatment of persons coinfected with HIV and HCV [35,43,44], and increase readmission rates and health care usage after surgery [45].

Our findings indicate a strong association between ORCs and HIV, an association that is even stronger among beneficiaries with HCV or HBV claims. For beneficiaries with ORCs, the odds ratios range from 5.0 for having claims for chronic HBV infection to 9.5 for having claims for acute HCV infection, compared with beneficiaries without ORCs; this range is more than the odds ratio of having claims for HIV alone (i.e., aOR, 2.3). A systematic review of viral hepatitis among injection-drug users estimated that worldwide, approximately 10.0 million and 6.4 million persons who inject drugs might have HCV antibody (anti-HCV) and total hepatitis B core antibody, respectively, and concluded that the prevalence of anti-HCV among persons who inject drugs is far greater than that of HIV [46]. Recently, HIV and viral hepatitis coinfection has become increasingly recognized as a major public health concern [47].

CDC reports that approximately one third of persons with HIV infection are coinfected with either $\mathrm{HBV}$ or HCV in the United States [47]. Additionally, hepatitis B vaccination rates among persons who inject drugs are lower than those among the general population [48], and no hepatitis $C$ vaccine is available $[7,49]$. Hence, an urgent need exists to increase hepatitis $B$ vaccination coverage and to develop a hepatitis $C$ vaccine for the general population; this need is especially crucial for persons who inject drugs.

Our results indicate that beneficiaries with ORCs and HIV, HBV, or HCV infections are more likely to have a claim for opioid or heroin overdose, compared with those without these infections. A prior study reported that opioid overdose deaths were high among those aged 25-64 years and death rates among non-Hispanic whites were 4 times higher than among Hispanic or black populations [50]. A recent study reported higher average inpatient stays and emergency department visits among 
patients aged $\geq 65$ years when comparing opioid-related inpatient stays and nonopioid-related stays during 2015 [16].

\section{Strengths and Limitations}

Strengths of this study include the large population-based samples from Medicare data for $98 \%$ of the US population aged $\geq 65$ years and also beneficiaries of all ages with qualifying conditions (e.g., end-stage renal disease). The majority of published studies have focused on opioid-related experiences and bloodborne infections primarily among young populations [51]. Our study allows for detailed analysis of opioid-related diagnoses and bloodborne infections among older adults or persons with disabilities who are more likely than younger adults to have adverse effects associated with opioid use [16].

Our findings are subject to certain limitations. First, this is a cross-sectional analysis of data for beneficiaries with claims for opioid-related diagnoses and selected bloodborne infections; therefore, a temporal association between persons with ORCs and the studied infections cannot be established. Second, this study used both ICD-9-CM and ICD-10-CM codes, and lack of diagnostic codes aligning directly with current clinical diagnostic criteria presents challenges. In our study, diagnostic codes were used to identify claims reflecting a broad spectrum of opioid use. Clinical terminology for certain opioid-related harms has varied over time [52]. For example, such terms as abuse are avoided to reduce stigma [53] but remain in diagnostic codes that do not clearly align with clinical diagnostic criteria [54]. Opioid use disorder, as defined by the Diagnostic and Statistical Manual of Mental Disorders (DSM-5) is "a problematic pattern of opioid use leading to clinically significant impairment or distress [55] (page 541)" characterized by patients having $\geq 2$ of 11 defined criteria (e.g., craving or strong desire or urge to use) within a 12-month interval [55]. Opioid misuse has been defined as including either the use of an illicit opioid or the nonmedical use of prescribed opioids [15].

An analysis of Medicare claims excluding diagnostic codes (e.g., for uncomplicated, unspecified opioid use) might reveal stronger associations of the selected infections with codes that clinicians might use for such opioid-related harms as opioid use disorder. The effects of the ICD-9-CM to ICD-10-CM transition in 2015 on the 2015 Medicare claims pertaining to opioid-related diagnoses and bloodborne infections were not assessed. A recent study examining trends in opioid-related inpatient stays using 2015 Healthcare Cost and Utilization Project data reported that $14.1 \%$ of the estimated opioid-related hospital stays were attributable to the transition to ICD-10-CM from ICD-9-CM in 2015 [56]. Therefore, our estimates might have been similarly affected. Third, our analysis used administrative claims data on infections that are underdiagnosed; therefore, the prevalence of HBV, HCV, or HIV are likely underestimated in this study. CDC recently examined National Health and Nutrition Examination Survey data and estimated that 0.38 million HCV antibody-positive persons were not included in the survey's sampling frame during 2013-2016 [57]. Fourth, our analysis included beneficiaries with these bloodborne infections based on diagnosis codes in claims data. We could not determine whether infections were new or chronic. Fifth, this study used diagnosis codes to define opioid-related claims and opioid overdose ignoring whether or not the claim requested reimbursement for those conditions. Sixth, our study examined the association while adjusting for county-level composite index or vulnerability scores. This index contains 15 county-level indicators associated with HIV or acute HCV infection [19]. We hypothesized that all beneficiaries in the same county had uniform socioeconomic attributes and ignored variations in other social factors or lifestyle changes among and between persons that might have influenced the selected health outcomes. Finally, this study did not account for other risk factors that have been correlated with opioid overdose (e.g., comorbid psychiatric and medical disorders) [58].

\section{Conclusions}

We observed small percentages of FFS beneficiaries with ORCs and with claims for HIV, HBV, or HCV infection. Strong, independent, and statistically significant factors associated with claims 
for opioid overdose or each of the bloodborne infections included ORCs and selected demographic attributes. These results can help guide interventions intended to reduce incidences of HIV, HCV, or HBV infections among Medicare beneficiaries with ORCs.

Supplementary Materials: The following are available online at http://www.mdpi.com/2077-0383/8/11/1768/s1. Table S1: Number and Percentage of Medicare Fee-for-Service Beneficiaries With or Without Opioid-related Claims Among Those Who Had Claims for HIV, HBV, or HCV, United States, 2015; Table S2: Number and Percentage of Medicare Fee-for-Service Beneficiaries Who Had Claims for Opioid-related Diagnoses, by Those with Claims for Opioid Overdose, United States, 2015; Table S3: Number and Percentage of Beneficiaries with Opioid Overdose Claims, ${ }^{\text {a }}$ by Demographic Characteristics Among the Medicare Fee-for-Service Beneficiaries Who Had or Did Not Have HIV, ${ }^{b}$ HBV, or HCV b Claims, United States, 2015; Table S4: Adjusted Odds Ratios (aORs) and 95\% Confidence Intervals (CIs) for Association of Opioid Overdose Claims with $\geq 1$ HIV, HBV, or HCV Infection Among Medicare Beneficiaries with Non-overdose Opioid-related Claims, United States, 2015; Table S5: Adjusted Odds Ratios (ORs) and 95\% Confidence Intervals (CIs) for Association of Heroin Overdose Claims Among Medicare Beneficiaries With Non-overdose Opioid-related Claims, United States, 2015.

Author Contributions: Conceptualization, M.-H.C.; R.M.; L.Z.S.; B.I.T.; Methodology, M.-H.C.; R.M.; B.I.T.; Software, M.-H.C.; Validation, M.-H.C.; R.M.; B.I.T.; Formal Analysis, M.-H.C.; R.M.; Investigation, M.-H.C.; R.M.; B.I.T.; Resources, M.-H.C.; R.M.; B.I.T.; Data Curation, M.-H.C.; R.M.; B.I.T.; Writing-Original Draft Preparation, M.-H.C.; R.M.; B.I.T.; Writing-Review \& Editing, M.-H.C.; R.M.; L.Z.S.; B.I.T.; Visualization, M.-H.C.; R.M.; B.I.T.; Supervision, B.I.T.; Project Administration, M.-H.C.; B.I.T.; Funding Acquisition, B.I.T.

Funding: None of the authors have any financial interest in the subject matter or materials discussed in the manuscript.

Acknowledgments: The authors thank the CMS staff for their data support and disclosure view, staff in the Chronic Condition Warehouse Help Desk for software and technical support, and staff in the Centers for Disease Control and Prevention's Center for Surveillance, Epidemiology, and Laboratory Services for their administrative support. We extend special thanks to C. Kay Smith, MEd, CDC, for editorial support.

Conflicts of Interest: The authors declare no conflict of interest.

Disclaimer: The findings and conclusions in this report are those of the authors and do not necessarily represent the official position of the Centers for Disease Control and Prevention.

\section{Appendix A}

Table A1. International Classification of Diseases, 9th Revision, Clinical Modification (ICD-9-CM) and International Classification of Diseases, 10th Revision, Clinical Modification (ICD-10-CM) Codes for HIV, HBV and HCV Infection Used in the Study.

\begin{tabular}{ccc}
\hline Disease & ICD-9-CM Code & ICD-10-CM Code \\
\hline HIV/AIDS & 042, V08, 079.53, or 795.71 & B20, Z21, B97.35, or R75 \\
\hline Hepatitis B & & \\
\hline Acute & $070.20,070.21,070.30,070.31$, or 070.52 & B16 \\
Chronic & $070.22,070.23,070.32,070.33$, or 070.42 & B17.0, B180.0, or B18.1 \\
\hline Hepatitis C & & \\
\hline Acute & 070.41 or 070.51 & B17.1 \\
Chronic & 070.44 or 070.54 & B18.2 \\
\hline
\end{tabular}

Abbreviations: $\mathrm{HBV}$, hepatitis $\mathrm{B}$ virus; $\mathrm{HCV}$, hepatitis $\mathrm{C}$ virus. 


\section{Appendix B}

Table A2. International Classification of Diseases, 9th Revision, Clinical Modification (ICD-9-CM) and International Classification of Diseases, 10th Revision, Clinical Modification (ICD-10-CM) Codes for Opioid-Related Claims ${ }^{a}$ and Heroin Overdose Used in the Study.

\begin{tabular}{|c|c|c|}
\hline Condition & ICD-9-CM Code & ICD-10-CM Code \\
\hline Opioid abuse & $30550,30551,30552$ & $\begin{array}{c}\text { F1110, F11120, F11121, F11122, F11129, F1114, } \\
\text { F11150, F11151, F11159, F11181, F11182, F11188, } \\
\text { F1119 }\end{array}$ \\
\hline $\begin{array}{l}\text { Opioid dependence and } \\
\text { unspecified use }\end{array}$ & $\begin{array}{l}30400,30401,30402, \\
30470,30471,30472\end{array}$ & $\begin{array}{c}\text { F1120, F11220, F11221, F11222, F11229, F1123, } \\
\text { F1124, F11250, F11251, F11259, F11281, F11282, } \\
\text { F11288, F1129, F1190, F11920, F11921, F11922, } \\
\text { F11929, F1193, F1194, F11950, F11951, F11959, } \\
\text { F11981, F11982, F11988, F1199 }\end{array}$ \\
\hline Opioid poisoning & $\begin{array}{l}96500,96501,96502 \\
96509,9701, \mathrm{E} 8500 \\
\mathrm{E} 8501, \mathrm{E} 8502\end{array}$ & $\begin{array}{c}\text { T400X1A, T400X1D, T400X1S, T4400X1S, T400X4A, } \\
\text { T400X4D, T400X4S, T401X1A, T401X1D, T401X1S, } \\
\text { T401X4A, T401X4D, T401X4S, T402X1A, T402X1D, } \\
\text { T402X1S, T402X4A, T402X4D, T402X4S, T403X1A, } \\
\text { T403X1D, T403X1S, T403X4A, T403X4D, T403X4S, } \\
\text { T404X1A, T404X1D, T404X1S, T404X4A, T404X4D, } \\
\text { T404X4S, T40601A, T40601D, T40601S, T40604A, } \\
\text { T40604D, T40604S, T40691A, T40691D, T40691S, } \\
\text { T40694A, T40694D, T40694S }\end{array}$ \\
\hline
\end{tabular}

Heroin poisoning

96501, E8500 $\mathrm{T} 40.1 \times 1 \mathrm{x}-1 \times 4 \mathrm{x}$

a Source: Moore BJ, Barrett ML. Case Study: Exploring How Opioid-Related Diagnosis Codes Translate From ICD-9-CM to ICD-10-CM. Rockville, MD: US Agency for Healthcare Research and Quality; 2018.

\section{References}

1. Centers for Disease Control and Prevention. Infectious Disease, Opioids and Injection Drug Use. Published 19 July 2018. Available online: https://www.cdc.gov/pwid/opioid-use.html (accessed on 13 August 2019).

2. Centers for Disease Control and Prevention. CDC's Response to the Opioid Overdose Epidemic: A Public Health Crisis. Published 11 January 2019. Available online: https://www.cdc.gov/opioids/strategy.html (accessed on 13 August 2019).

3. Scholl, L.; Seth, P.; Kariisa, M.; Wilson, N.; Baldwin, G. Drug and opioid-involved overdose deaths-United States, 2013-2017. MMWR Morb. Mortal. Wkly. Rep. 2018, 67, 1419-1427. [CrossRef] [PubMed]

4. Peters, P.J.; Pontones, P.; Hoover, K.W.; Patel, M.R.; Galang, R.R.; Shields, J.; Blosser, S.J.; Spiller, M.W.; Combs, B.; Switzer, W.M.; et al. HIV infection linked to injection use of oxymorphone in Indiana, 2014-2015. N. Engl. J. Med. 2016, 375, 229-239. [CrossRef] [PubMed]

5. Centers for Disease Control and Prevention. HIV among People Who Inject Drugs. Published 15 March 2019. Available online: https://www.cdc.gov/hiv/group/hiv-idu.html (accessed on 13 August 2019).

6. Henry J Kaiser Family Foundation. HIV and the Opioid Epidemic: 5 Key Points. Published 2019. Available online: https://www.kff.org/hivaids/issue-brief/hiv-and-the-opioid-epidemic-5-key-points/ (accessed on 13 August 2019).

7. World Health Organization HIV/AIDS Programme. Guidance on Prevention of Viral Hepatitis B and C among People Who Inject Drugs: Policy Brief. Published 2012. Available online: http://apps.who.int/iris/bitstream/handle/10665/75192/WHO_HIV_2012.18_eng.pdf;jsessionid= D9854F67FD3BD4971C81259272696CB9?sequence=1 (accessed on 13 August 2019).

8. Center for Substance Abuse Treatment. Medication-Assisted Treatment for Opioid Addiction in Opioid Treatment Programs; Report No.: (SMA) 12-4214; Substance Abuse and Mental Health Services Administration: Rockville, MD, USA, 2005.

9. Centers for Disease Control and Prevention. Hepatitis C Kills More Americans Than Any Other Infectious Disease: New CDC Studies Underscore Urgency of Hepatitis C Testing and Treatment, Especially for Baby 
Boomers. Published 4 May 2016. Available online: https://www.cdc.gov/media/releases/2016/p0504-hepcmortality.html (accessed on 13 August 2019).

10. Centers for Disease Control and Prevention. Surveillance for Viral Hepatitis-United States. 2016; Published 16 April 2018. Available online: https://www.cdc.gov/hepatitis/statistics/2016surveillance/pdfs/ 2016HepSurveillanceRpt.pdf (accessed on 13 August 2019).

11. Bruneau, J.; Roy, E.; Arruda, N.; Zang, G.; Jutras-Aswad, D. The rising prevalence of prescription opioid injection and its association with hepatitis C incidence among street-drug users. Addiction 2012, 107, 1318-1327. [CrossRef] [PubMed]

12. National Viral Hepatitis Roundtable. Dual Epidemics: Opioids and Hepatitis, C. Available online: http://nvhr. org/sites/default/files/.users/u33/One\%20Pager\%20on\%20HCV\%20and\%20Opioid\%20Crisis.pdf (accessed on 13 August 2019).

13. Zibbell, J.E.; Asher, A.K.; Patel, R.C.; Kupronis, B.; Iqbal, K.; Ward, J.W.; Holtzman, D. Increases in acute hepatitis $C$ virus infection related to a growing opioid epidemic and associated injection drug use, United States, 2004 to 2014. Am. J. Public Health 2018, 108, 175-181. [CrossRef] [PubMed]

14. Centers for Disease Control and Prevention. Increase in Hepatitis C Infections Linked to Worsening Opioid Crisis. Published 21 December 2017. Available online: https://www.cdc.gov/nchhstp/newsroom/2017/ hepatitis-c-and-opioid-injection-press-release.html (accessed on 13 August 2019).

15. Substance Abuse and Mental Health Science Administration. The CBHSQ Report: Opioid Misuse Increases among Older Adults. Published 25 July 2017. Available online: https://www.samhsa.gov/data/sites/default/ files/report_3186/Spotlight-3186.html (accessed on 13 August 2019).

16. Weiss, A.J.; Heslin, K.C.; Barrett, M.L.; Izar, R.; Bierman, A.S. Opioid-Related Inpatient Stays and Emergency Department Visits among Patients Aged 65 Years and Older, 2010 and 2015. Healthcare Cost and Utilization Project Statistical Brief \#244. Published 12 September 2018. Available online: https://www.hcup-us.ahrq.gov/ reports/statbriefs/sb244-Opioid-Inpatient-Stays-ED-Visits-Older-Adults.jsp (accessed on 13 August 2019).

17. Rubin, R. Opioid-related problems increasing among older adults. JAMA 2018, 320, 2067. [CrossRef]

18. National Academies of Sciences, Engineering, and Medicine. Pain Management and the Opioid Epidemic: Balancing Societal and Individual Benefits and Risks of Prescription Opioid Use; The National Academies Press: Washington, DC, USA, 2017.

19. Van Handel, M.M.; Rose, C.E.; Hallisey, E.J.; Kolling, J.L.; Zibbell, J.E.; Lewis, B.; Bohm, M.K.; Jones, C.M.; Flanagan, B.E.; Siddiqi, A.E.A.; et al. County-level vulnerability assessment for rapid dissemination of HIV or HCV infections among persons who inject drugs, United States. J. Acquir. Immune Defic. Syndr. 2016, 73, 323-331. [CrossRef]

20. Centers for Medicare \& Medicaid Services. CMS proposes Medicare Advantage and Part D Payment and Policy Updates to Provide New Benefits for Enrollees, New Protections to Combat Opioid Crisis. Published 1 February 2018. Available online: https://www.cms.gov/Newsroom/MediaReleaseDatabase/Press-releases/ 2018-Press-releases-items/2018-02-01.html (accessed on 13 August 2019).

21. Research Data Assistance Center. Data File Search. Published 2019. Available online: http://www.resdac.org/ cms-data/search?f\%5b0\%5d=im_field_data_file_category\%3A46 (accessed on 13 August 2019).

22. Leibowitz, A.A.; Desmond, K. Identifying a sample of HIV-positive beneficiaries from Medicaid claims data and estimating their treatment costs. Am. J. Public Health 2015, 105, 567-574. [CrossRef]

23. Centers for Disease Control and Prevention. International Classification of Diseases, Ninth Revision, Clinical Modification (ICD-9-CM). Published 6 November 2015. Available online: https://www.cdc.gov/nchs/icd/ icd9 cm.htm (accessed on 13 August 2019).

24. Centers for Disease Control and Prevention. International Classification of Diseases, Tenth Revision, Clinical Modification (ICD-10-CM). Published 5 August 2019. Available online: https://www.cdc.gov/nchs/icd/ icd10cm.htm (accessed on 13 August 2019).

25. Moore, B.J.; Barrett, M.L. Case Study: Exploring How Opioid-Related Diagnosis Codes Translate from ICD-9-CM to ICD-10-CM.; US Department of Health and Human Services, Agency for Healthcare Research and Quality: Rockville, MD, USA, 2017. Available online: https://www.hcup-us.ahrq.gov/datainnovations/ICD10CaseStudyonOpioid-RelatedIPStays042417.pdf (accessed on 13 August 2019).

26. Chronic Conditions Data Warehouse. Data Dictionaries. Available online: https://www2.ccwdata.org/web/ guest/data-dictionaries (accessed on 22 October 2019). 
27. Morden, N.E.; Munson, J.C.; Colla, C.H.; Skinner, J.S.; Bynum, J.P.; Zhou, W.; Meara, E.R. Prescription opioid use among disabled Medicare beneficiaries: Intensity, trends, and regional variation. Med. Care 2014, 52, 852-859. [CrossRef]

28. Centers for Disease Control and Prevention. Vital Signs: Opioid Overdoses Treated in Emergency Departments. Published 16 March 2018. Available online: https://www.cdc.gov/vitalsigns/opioid-overdoses/ index.html (accessed on 13 August 2019).

29. Guy, G.P., Jr.; Zhang, K.; Bohm, M.K.; Losby, J.; Lewis, B.; Young, R.; Murphy, L.B.; Dowell, D. Vital signs: Changes in opioid prescribing in the United States, 2006-2015. MMWR Morb. Mortal. Wkly. Rep. 2017, 66, 697-704. [CrossRef]

30. Schieber, L.Z.; Guy, G.P., Jr.; Seth, P.; Young, R.; Mattson, C.L.; Mikosz, C.A.; Schieber, R.A. Trends and patterns of geographic variation in opioid prescribing practices by state, United States, 2006-2017. JAMA Netw. Open 2019, 2, e190665. [CrossRef]

31. Nataraj, N.; Zhang, K.; Guy, G.P., Jr.; Losby, J.L. Identifying opioid prescribing patterns for high-volume prescribers via cluster analysis. Drug Alcohol Depend. 2019, 197, 250-254. [CrossRef] [PubMed]

32. Becker, W.C.; Gordon, K.; Edelman, E.J.; Kerns, R.D.; Crystal, S.; Dziura, J.D.; Fiellin, L.E.; Gordon, A.J.; Goulet, J.L.; Justice, A.C.; et al. Trends in any and high-dose opioid analgesic receipt among aging patients with and without HIV. AIDS Behav. 2016, 20, 679-686. [CrossRef] [PubMed]

33. Harris, A.M. Increases in acute hepatitis B virus infections-Kentucky, Tennessee, and West Virginia, 2006-2013. MMWR Morb. Mortal. Wkly. Rep. 2016, 65, 47-50. [CrossRef] [PubMed]

34. Kalichman, S.C.; Washington, C.; Kegler, C.; Grebler, T.; Kalichman, M.O.; Cherry, C.; Eaton, L. Continued substance use among people living with HIV-hepatitis-C co-infection and receiving antiretroviral therapy. Subst. Use Misuse 2015, 50, 1536-1543. [CrossRef] [PubMed]

35. McCance-Katz, E.F. Treatment of opioid dependence and coinfection with HIV and hepatitis $\mathrm{C}$ virus in opioid-dependent patients: The importance of drug interactions between opioids and antiretroviral agents. Clin. Infect. Dis. 2005, 41 (Suppl. 1), S89-S95. [CrossRef] [PubMed]

36. Edelman, E.J.; Gordon, K.; Becker, W.C.; Goulet, J.L.; Skanderson, M.; Gaither, J.R.; Braden, J.B.; Gordon, A.J.; Kerns, R.D.; Justice, A.C.; et al. Receipt of opioid analgesics by HIV-infected and uninfected patients. J. Gen. Intern. Med. 2013, 28, 82-90. [CrossRef]

37. Gaither, J.R.; Goulet, J.L.; Becker, W.C.; Crystal, S.; Edelman, E.J.; Gordon, K.; Kerns, R.D.; Rimland, D.; Skanderson, M.; Weisberg, D.F.; et al. Guideline-concordant management of opioid therapy among human immunodeficiency virus (HIV)-infected and uninfected veterans. J. Pain 2014, 15, 1130-1140. [CrossRef]

38. Bohnert, A.S.; Valenstein, M.; Bair, M.J.; Ganoczy, D.; McCarthy, J.F.; Ilgen, M.A.; Blow, F.C. Association between opioid prescribing patterns and opioid overdose-related deaths. JAMA 2011, 305, 1315-1321. [CrossRef]

39. Weisberg, D.F.; Gordon, K.S.; Barry, D.T.; Becker, W.C.; Crystal, S.; Edelman, E.J.; Gaither, J.; Gordon, A.J.; Goulet, J.; Kerns, R.D.; et al. Long-term prescription of opioids and/or benzodiazepines and mortality among HIV-infected and uninfected patients. J. Acquir. Immune Defic. Syndr. 2015, 69, 223-233. [CrossRef]

40. Bing, E.G.; Burnam, M.A.; Longshore, D.; Fleishman, J.A.; Sherbourne, C.D.; London, A.S.; Turner, B.J.; Eggan, F.; Beckman, R.; Vitiello, B.; et al. Psychiatric disorders and drug use among human immunodeficiency virus-infected adults in the United States. Arch. Gen. Psychiatry 2001, 58, 721-728. [CrossRef]

41. Silverberg, M.J.; Ray, G.T.; Saunders, K.; Rutter, C.M.; Campbell, C.I.; Merrill, J.O.; Sullivan, M.D.; Banta-Green, C.J.; Von Korff, M.; Weisner, C. Prescription long-term opioid use in HIV-infected patients. Clin. J. Pain 2012, 28, 39-46. [CrossRef] [PubMed]

42. Roy, S.; Ninkovic, J.; Banerjee, S.; Charboneau, R.G.; Das, S.; Dutta, R.; Kirchner, V.A.; Koodie, L.; Ma, J.; Meng, J.; et al. Opioid drug abuse and modulation of immune function: Consequences in the susceptibility to opportunistic infections. J. Neuroimmune Pharmacol. 2011, 6, 442-465. [CrossRef] [PubMed]

43. Batkis, M.F.; Treisman, G.J.; Angelino, A.F. Integrated opioid use disorder and HIV treatment: Rationale, clinical guidelines for addiction treatment, and review of interactions of antiretroviral agents and opioid agonist therapies. AIDS Patient Care STDS 2010, 24, 15-22. [CrossRef] [PubMed]

44. McCance-Katz, E.F.; Rainey, P.M.; Smith, P.; Morse, G.D.; Friedland, G.; Boyarsky, B.; Gourevitch, M.; Jatlow, P.; McCance-Katz, E.F.; Mccance-Katz, E.F. Drug interactions between opioids and antiretroviral medications: Interaction between methadone, LAAM, and delavirdine. Am. J. Addict. 2006, 15, 23-34. [CrossRef] 
45. Gupta, A.; Nizamuddin, J.; Elmofty, D.; Nizamuddin, S.L.; Tung, A.; Minhaj, M.; Mueller, A.; Apfelbaum, J.; Shahul, S. Opioid abuse or dependence increases 30-day readmission rates after major operating room procedures: A National Readmissions Database Study. Anesthesiology 2018, 128, 880-890. [CrossRef]

46. Nelson, P.K.; Mathers, B.M.; Cowie, B.; Hagan, H.; Jarlais, D.D.; Horyniak, D.; Degenhardt, L. Global epidemiology of hepatitis B and hepatitis C in people who inject drugs: Results of systematic reviews. Lancet 2011, 378, 571-583. [CrossRef]

47. Centers for Disease Control and Prevention. HIV and Viral Hepatitis. Published June 2017. Available online: https://www.cdc.gov/hiv/pdf/library/factsheets/hiv-viral-hepatitis.pdf (accessed on 13 August 2019).

48. Hep B United. Hepatitis B and the Opioid Epidemic. Published April 2018. Available online: https://www.adultvaccinesnow.org/wp-content/uploads/2018/06/HBU-HBV-and-Opioid-Overview_ Updated-April-2018-pdf.pdf (accessed on 13 August 2019).

49. Page, K.; Cox, A.; Lum, P.J. Opioids, hepatitis C virus infection, and the missing vaccine. Am. J. Public Health 2018, 108, 156-157. [CrossRef]

50. Chen, L.H.; Hedegaard, H.; Warner, M. Drug-Poisoning Deaths Involving Opioid Analgesics: United States, 1999-2011; NCHS Data Brief, No. 166; National Center for Health Statistics: Hyattsville, MD, USA, 2014; pp. 1-8.

51. Zibbell, J.E.; Iqbal, K.; Patel, R.C.; Suryaprasad, A.; Sanders, K.J.; Moore-Moravian, L.; Serrecchia, J.; Blankenship, S.; Ward, J.W.; Holtzman, D. Increases in hepatitis C virus infection related to injection drug use among persons aged $\leq 30$ years-Kentucky, Tennessee, Virginia, and West Virginia, 2006-2012. MMWR Morb. Mortal. Wkly. Rep. 2015, 64, 453-458.

52. Mangione, M.P.; Crowley-Matoka, M. Improving pain management communication: How patients understand the terms "opioid" and "narcotic". J. Gen. Intern. Med. 2008, 23, 1336-1338. [CrossRef]

53. Saitz, R. Things that work, things that don't work, and things that matter-Including words. J. Addict. Med. 2015, 9, 429-430. [CrossRef]

54. Peterson, C.; Xu, L.; Mikosz, C.A.; Florence, C.; Mack, K.A. US hospital discharges documenting opioid use disorder without opioid overdose or treatment services, 2011-2015. J. Subst. Abuse Treat. 2018, 92, 35-39. [CrossRef] [PubMed]

55. American Psychiatric Association. Diagnostic and Statistical Manual of Mental Disorders, 5th ed.; American Psychiatric Publishing: Arlington, VA, USA, 2013.

56. Heslin, K.C.; Owens, P.L.; Karaca, Z.; Barrett, M.L.; Moore, B.J.; Elixhauser, A. Trends in opioid-related inpatient stays shifted after the US transitioned to ICD-10-CM diagnosis coding in 2015. Med. Care 2017, 55, 918-923. [CrossRef] [PubMed]

57. Hofmeister, M.G.; Rosenthal, E.M.; Barker, L.K.; Rosenberg, E.S.; Barranco, M.A.; Hall, E.W.; Edlin, B.R.; Mermin, J.; Ward, J.W.; Ryerson, A.B.; et al. Estimating prevalence of hepatitis C virus infection in the United States, 2013-2016. Hepatology 2019, 69, 1020-1031. [CrossRef] [PubMed]

58. Webster, L.R. Risk factors for opioid-use disorder and overdose. Anesth. Analg. 2017, 125, 1741-1748. [CrossRef]

(C) 2019 by the authors. Licensee MDPI, Basel, Switzerland. This article is an open access article distributed under the terms and conditions of the Creative Commons Attribution (CC BY) license (http://creativecommons.org/licenses/by/4.0/). 